\title{
An analysis of challenges in the teaching of problem solving in Grade 10 mathematics
}

\author{
TJMOLOI
}

\begin{abstract}
The paper focuses on challenges in the teaching of problem-solving in Grade 10 Mathematics, which may emanate from ignoring the background environment of the child (Graven \& Schafer, 2013:4). It is important to affirm what learners know because their background knowledge is influenced by environmental surroundings (Leung, 2008:145), including social and cultural practices. The Department of Basic Education Report (2009) shows that the same topics in which Grade 10 Mathematics learners performed poorly corresponded with those in which they did poorly at the end of their Grade 12 examinations. The study is framed by community cultural wealth theory (Yosso, 2005), which posits knowledge as excluding communities. Rocha-Schmid (2010:344) contends that it is not correct to view excluded communities as objects for rehabilitation, but rather they should be conceived by a Freirean emancipatory project that perceives subaltern communities as authentic beings capable of engaging mathematical concepts in creative endeavours and critical thinking. Hence, the study asserts that it is crucial that parents, traditional leaders and community leaders, play a crucial role in the teaching and learning of Grade 10 Mathematics, so as to alleviate the identified challenges. The study utilised participatory action research (PAR) methods, which recognise community members as experts, and the empowerment of communities to find their own solutions to local issues (Moana, 2010:1). The researcher puts together a team of community members, the school population and education district officials as participants in the study. Each challenge was outlined and analysed using critical discourse analysis (CDA), enabling the participants to use the spoken/written word as evidence of the interpretation made at both the levels of discursive practice and social structures, to extract a deeper meaning and to make repertoires of each participant (Francis, 2012:18; Mahlomaholo, 2012a:51, 2012b:104).
\end{abstract}

Key words: Mathematics; Grade 10; problem-solving.

\section{Introduction and background}

The paper seeks to explain why subaltern learners are performing badly in Mathematics and provides solutions to the poor performance of learners. The Department of Basic Education (DBE) Reports of 2009 and 2010 show that, nationally, the Grade 12 Mathematics results in 2008, 2009 and 2010 stood at 45\%, 95\%, 46\% and 47.4\% respectively. In the Free State province, results were respectively $77.63 \%, 53.3 \%$ and $48.4 \%$. The Annual National

1 Tshele J Moloi (MEd) is a lecturer of Mathematics Education in the School of Mathematics, Natural Sciences and Technology Education. His research focuses on indigenous knowledge and its use in Mathematics Education. Email: moloijt@qwa.ufs.ac.za

TD The Journal for Transdisciplinary Research in Southern Africa, 9(3), Special edition, December 2013, pp. 480492. 
Assessments (ANA) Report 2011 shows that, in the Free State, 74\% of learners in Grade 6 failed Mathematics, which is a major concern for educational and non-professional stakeholders (Tucker, 2010:134), and notes that the marginalised learners are in the majority in public schools.

Leonard (2008:156) reported that African American children did not score as well in Mathematics as did other ethnic groups, finding that parents were too negligent about their children's schoolwork and the children received mixed messages about school from their community. The involvement of parents and community did show significant improvement in Mathematics performance, with Reddy (2006:1) finding that the South African government had accentuated the centrality of Mathematics as part of human development strategy. Whether Mathematics performance was good or bad this at least indicates that the education system in general was in a healthy condition.

The study refutes the argument made by Reddy (2006:1) that most South African citizens meet Mathematics for the first and last time in the schooling system. The paper argues that subaltern learners are exposed to various environmental backgrounds which are very rich in Mathematics. This is echoed by Leung (2008:136,145), Ruthven, (2001:355) and Tucker (2010:5), for whom teaching Mathematics requires acculturation by bringing in the everyday, historical and community cultures into the classroom. Children observe and participate in many mathematical events before they begin nursery or statutory schooling. This suggests that mathematics needs to be relevant to their lives.

Teaching and learning of mathematics is skewed negatively, causing educators to view learners according to the deficit model (Leung, 135; Warren \& Miller, 2013:4). They believe that learners learn Mathematics concepts such as patterns, relationships for the first time in a classroom.For Ruthven (2001:357,358), scholarly mathematics has become so detached from its grounding in familiar phenomena and so recursively redefined that it cannot provide adequate referents for much of school and out-of-school mathematics. The radical change that is increasingly informing the 'enculturation' of mathematics is a desperate attempt to prove that it is not foreign to the child's everyday experience. Tucker $(2010: 5,6)$ acknowledges the influence of Vygotsky's theory on mathematics teaching, particularly the child's own experiences. As learners interact with day-to-day activities or tasks they are operating in rich mathematical contexts which introduce them to concepts and skills. As learners play at home, there are mathematical concepts such as patterns, relatioships, geometrical concepts which are frequently used.

Educators who view learners by the deficit model maintain that the children's environment is not rich in mathematical concepts, hence their inaccurate stance of viewing mathematics as an object aloof from human practices. As mathematics is viewed from narrow perspectives it has been taught in a linear way, with the creativity of the child being ignored. Matthews et al. (2005:3) and Vithal et al. (2005) write that the Mathematics curriculum was driven by an ideology characterised by a deep disrespect for subaltern communities' mathematical knowledge. Reddy (2006:393) argues that the ideology characterised by deep disrespect of excluded learners' mathematical knowledge is the perpetuation of the stereotypical thinking of Verwoerd, that it is pointless teaching marginalised mathematics to people who cannot use it in practice.

The study maintained that the background environment of the child is key to the teaching and learning of mathematics. Various sources (Barton, 2008:128; Department of Education 
(DoE), 2003:9; Department of Basic Education (DBE), 2009:8, Gerdes, 2001; Leonard, 2008:166; Leung, 2008:136; Tucker 2010:5) perceive mathematics as a human activity practiced by all cultures, claiming that, like all other forms of knowledge, it should be understood as it operates within a cultural context. The are indigenous games such as diketo(coordination game), kgati(rope jumping), morabara (board game) which are infused with lot of mathematical concepts and skills.

Graven and Schafer (2013:4) assert that it is important to affirm what learners know because they acquire new knowledge through relating new things to what already exists in our knowledge schema. The contextualisation of mathematics has been recognised as a strategy (Ruthven, 2001:358) to improve educational outcomes for marginalised learners in mathematics (Matthews \& Watego, 2005:6). By translating 'real-life' activities into the classroom, mathematics becomes more accessible and relevant to learners. For instances the playing of kgati, assist learners to visualise the patterns (sequences) in practice. If one is in round one, in the playing of kgati, if the player is in round one, where the stones are pushed into the hole, the general pattern of pushing the stones into the hole can be demonstrated by the equation: $f(m)=-\frac{m}{2}+10$ (where $m$ is the number of throwing the ghoen up in the air, and $f(m)$ are number of stones pushed into the hole.)

Furthermore, the Australian Association of Mathematics Teachers (2006:2) emphasised that excellent teachers of mathematics have a thorough knowledge of learners, which includes knowledge of their social and cultural contexts, as well as the mathematics they know and use, and their preferred ways of learning. In contextualising mathematics the use of indigenous games will be considered as the approach that allows one to tap into the social environment of the children. Also indigenous games allow learners to discover mathematics concepts embedded in them. This is in line with Mahlomaholo's (2012:5) argument that the learning environment includes the learner's social-cultural background which he/she brings with to the classroom. The teachers in the classroom need to use the social environment to explain abstract mathematical concepts. For instance the independent and dependent variables can be explained using diketo game. The ghoen thrown in the air exemplify the independent variable and scooping the stones out of the hole or pushing them in the hole illustrates the depedent variables.

On the other hand, when analysing and interpreting the collected data, the researcher utilised critical discourse analysis (CDA) to assist in extracting a deeper meaning of the spoken words as evidence for the interpretation at both the levels of discursive practice and social structures. $\mathrm{CDA}$ is also used to gauge how texts of different kinds reproduce power, inequalities and other factors of social justice in society (Francis, 2012:18; Mahlomaholo, 2012:51,104; Perakyla \& Ruusuvuori, 2011:531).

The texts interpreted in this research paper were transcribed verbatim form videotapes, in a mixture of Sesotho, isiZulu and English. As Mahlomaholo (2012:10) and Van Laren and Goba (2013:2) write, participants should be allowed to feel comfortable through whatever means necessary, that is, they should express themselves in whatever language they feel comfortable with. Young children who learn in a second language see their academic progress being inhibited, unlike those who learn in their mother tongue, as the latter gain cultural, social, linguistic and cognitive knowledge, which the community's cultural knowledge theory embraces (Leung, 2008:139; Van Laren \& Goba, 2013:2). Francis (2012:49) contends that this allows the self or the teller to be at the centre of the story, and as Perakyla and 
Ruusuvuori (2011:530) and Wodak and Meyer (2009:3) posit, CDA encourages new questions, responses and thoughts, through reading and rereading the empirical material. By so doing, qualitative researchers try to pin down their key themes and thereby draw a picture of the presuppositions and meanings that constitute the cultural world.

\section{The lens}

The research was conducted through a lens that found no deficit in the knowledge that children brought from home, but rather it is highly valued. Yosso (2005:76) shows that the community's cultural wealth validates the knowledge that learners brought from home. Community cultural wealth theory views the knowledge as very rich in mathematical concepts and skills. The tenets of community cultural wealth theory (navigational knowledge, aspirational knowledge, social skills, linguistic skills, familial skills) are very rich in mathematical concepts and skills. Children come to school having inherented these principles of community cultural wealth. On the other side, Chilisa (2012:40) argues that the positivistic approach, when conducting research, seeks to discover laws that are generalisable and govern the universe, unlike the community's cultural wealth theory, which focuses on empowering marginalised communities and making them aware that the knowledge and skills they possess are so useful that they can be beneficial to the teaching and learning of mathematics. Post-positivist theories on community cultural wealth are perceived as decolonising tools that ruptured the hegemonic Western methods of research, in which truth is viewed in one colour. Decolonising theories opposed the notion that truth is based on precise observation and measurement that is verifiable, and that through scientific method a reality can be reached (Odora-Hoppers, 2000:286; McGregor \& Murnane 2010:14). Postpositivism theories maintained that reality is constructed within a social historical context and is further shaped by ethnic, cultural, gender, social and political values and mediated by power relations.

The arguments raised above suggest that the positivist approach teaches mathematics from an objective point of view, with the teacher an active participant in class. The teacher is regarded as the powerful person transmitting the knowledge into the minds of learners. Learners passively absorb the information given by the one in authority. In contrast, community cultural knowledge theory maintains that all participants in the research can play a vital role in the teaching and learning of mathematics. The classroom participants, among others can include learners, parents, teachers from mathematics and other social sciences subjects, community members, and education officials at district or provincial levels. This is further illustrated by Mahlomaholo (2012:4), who argues that the parents of learners and other community members who are custodians of, and who create and recreate this community cultural wealth, featured prominently in the mathematics learning and teaching environment. One's background environment has a great impact on understanding the mathematical concepts. For instance, the Australian Association of Mathematics Teachers (2006:2) suggests that excellent mathematics teachers need to encourage and involve parents as role model for learners in the teaching and learning of mathematics. 


\section{Methodology and design}

As the study is conducted within the parameters of community cultural wealth theory, the appropriate methodology encompassing the theory is Participatory Action Research (PAR). The research team comprised traditional leaders, parents from the community, departmental officials at district level, the school community, consisting of Grade 10 learners, mathematics and Life Orientation educators, the deputy principal, and one representative from higher education. Baquedano-Lopez, Alexander and Hernandez (2013:149), Berwick and Bennet (2008:14), Howard and Perry (2008:4) have demonstrated that in establishing learning teams it was important for them to consist of teachers, aboriginal educators and the local community, who developed contextual, multistage mathematics units that suited the learning needs of the local aboriginal learners. They further encouraged school communities, educational regions and dioceses or districts to consider establishing local/regional directories of aboriginal organisations and government departments that might be able to assist in teaching and gathering information of use in the classroom environment in the teaching of mathematics.

PAR as a framework emphasises redressing power imbalances between researchers (generally academics) and research participants (generally non-academics). Learners are given elevated status because of the marginalised knowledge they possess.In addition, it is built upon the idea that knowledge generated is a collaborative process in which the participants' diverse experiences and skills are critical to the outcome of the work project (Brydon-Miller, Kral, Maguire, Noffke \& Sabhlok, 2011:387; de Leeuw, Cameron, Greenwood, 2012:184). This argument helps in understanding that the teaching of mathematics in a classroom is not only the work of the teachers. Parents and learners who possess the various skills can also be of assistance in demonstrating how the indigenous games are played, whilst teachers and learners and other stakeholders can extract the mathematics demonstrated in such games. As Brydon-Miller et al. (2011:387) argue, the collaboration of the school community, traditional leaders, subaltern communities and education district officials in solving the concrete community problems will benefit all involved participants.

This also touches on the onto-semiotic approach (Font, Godino, D'amore, 2007:2-3), with dual dimensions that need to be considered when teaching and learning mathematics. The ostensive facet as the component of the onto-semiotic approach ,is illustrated through demonstration by subaltern communities, when performing the games, and nonostensive(likewise as the component of onto -semiotic approach)is denoted by the other parties in extracting the mathematical concepts portrayed by playing games. The ontosemiotic approach emphasised the usefulness of cooperation among different partners in addressing the concrete community problems. Each one will bring different skills and knowledge to solve the community problem.

PAR opens new spaces in which teachers in the classrooms can work outside conventional way of teaching mathematics. The collaborative approaches in the teaching of mathematics allow for mutual benefit for all involved in the research in building a community's capacity of teaching mathematics to subaltern learners. Most importantly, the subaltern communities are given a voice in enhancing excluded learners by using cultural appropriateness in mathematics learning (Berwick \& Bennet, 2008:14). 


\section{Findings and discussions}

The research project has identified numerous challenges in the teaching of problem-solving in Grade 10 mathematics classes, in line with what the DBE identified in its annual reports.

Traditional leaders are sceptical about assisting in the research project, which in turn benefits Mathematics learners

At first the trips to local communities to seek support for the suggested research project found some hesitant to be part of the group, working together to teach problem solving in Grade 10 Mathematics classes. One traditional leader, Rakgomo, argued that

...Le a re nanarela, le utswe tsebo ya rona molemomg wa lona.... (... you are swiftly

following us; steal our valuable knowledge for your own good...).

The extract indicates that the positivist research which prevailed for a long time in this area had had serious repercussions. The local communities felt that they had just been exploited by researchers, and after that had 'vanished' with their valuable information. This shows that the local communities viewed the researchers as powerful individuals, whereby they used power wrongly to benefit themselves, excluding the proponents of the information. They felt that they were not part of the venture as they were ridiculed and shown up for the inferiority of their knowledge to the Western scientific equivalent. Hence, initially some members of the subaltern communities felt separate from the initiatives. Tucker $(2010: 144)$ asserts that it is important that there are several strategies for involving parents and local communities in playful mathematics, further engaging them in cultural practices (demonstrating the play of indigenous games). Initiatives show them that marginalised knowledge they possess is very rich in mathematics, and this will further validate that it is creative, exciting and an activity to be enjoyed with their children.

After several meetings with the excluded communities they understood that the research project would be of benefit to them and their children in the future. The mode in which the meetings were conducted was a welcoming atmosphere in which their input was acknowledged.

\section{Alienation of subaltern communities in the public schools}

Many educational legislative imperatives and policy directives of the democratic South African state dictate that schools should be integral parts of the communities within which they occur. The structures within public schools must change to empower teachers, teacher mentors, and community members and so make schools part of their communities rather than separate (oppressive) entities. The families and parents give support to their children for them to do well at school, which has thus to find ways of visiting parents in their own homes and communities so as to ensure their involvement in the learning of their children. Creative strategies should be initiated to encourage parents, in particular, to become part of the educative process, in the teaching of mathematics. Involving parents and subaltern communities in their children's education plays a significant role in the children's engagement with the learning of mathematics (Leonard, 2008:157; Mahlomaholo, 2012:57; Matthews, Watego et al., 2005:6, Tucker, 2010:140).

The extract below is in line with Maistry's (2013:31) argument concerning the dominant discourses that were still prevalent: 
In confronting and dislodging oppressive discourses, Ramasimo (the Researcher) reiterated the fact that: 'tsebo ena eo re tlo e fumana mokgoping ona, nna, mmoho le lona, batswadi, matitjhere, le bana, le bohle ba nang le tjantjello thutong, ke tsebo e tlo tswela setjhabana sena sa morena molemo. Ke hore bana ba rona ba tla hlahisa ditholwana tse ntle thutong ena ya mmetse. (The knowledge to be gathered and shared by this group (myself, you as traditional leaders, parents, teachers and learners and all interested partners in education), will be of great benefit to us, in particular to our children who will perform well in mathematics).

The extract shows that group efforts are appreciated for the benefit of the whole group. Nouns such as 're' 'we', 'mokgoping ona' ('in this group') show that as a group working together we can achieve more and this contributes to sustainable learning in the teaching and learning of problem-solving in mathematics (Tucker, 2010:146). Local communities realised that the marginalised knowledge they possess is of help in the teaching of mathematics. The play of diketo, using ten small stones and the big one(ghoen), which is thrown in the air as the player scooped or placedthe stones in the hole. The Table A, below shows the pattern revealed the game. The observation made was that if there there then stones used, to complete the game there are nineteen (19) throws to be made. The general conclusion is made that for $n$ stones use in play, there are $2 n-1$ throws to be made to complete the game.

\begin{tabular}{|l|l|l|l|}
\hline $\begin{array}{l}\text { Throwing the ghoen } \\
\text { up }\end{array}$ & $\begin{array}{l}\text { No. of stones scooped } \\
\text { out of the hole }\end{array}$ & $\begin{array}{l}\text { Throwing the } \\
\text { ghoen up }\end{array}$ & $\begin{array}{l}\text { No.of stones placed } \\
\text { into the hole }\end{array}$ \\
\hline $1^{\text {st }}$ throw & 10 & $2^{\text {nd }}$ throw & 9 \\
\hline $3^{\text {rd }}$ throw & 9 & $4^{\text {th }}$ throw & 8 \\
\hline $5^{\text {th }}$ throw & 8 & $6^{\text {th }}$ throw & 7 \\
\hline $7^{\text {th }}$ throw & 7 & $8^{\text {th }}$ throw & 6 \\
\hline $9^{\text {th }}$ throw & 6 & $10^{\text {th }}$ throw & 5 \\
\hline $11^{\text {th }}$ throw & 5 & $12^{\text {th }}$ throw & 4 \\
\hline $13^{\text {th }}$ throw & 4 & $14^{\text {th }}$ throw & 3 \\
\hline $15^{\text {th }}$ throw & 3 & $16^{\text {th }}$ throw & 2 \\
\hline $17^{\text {th }}$ throw & 2 & $18^{\text {th }}$ throw & 1 \\
\hline $19^{\text {th }}$ throw & 1 & \multicolumn{2}{|l}{} \\
\hline
\end{tabular}

TABLE A

From the table, it was obtained that the general pattern of scooping the stone sout of the hole can be described as $\boldsymbol{f}(\boldsymbol{n})=-\frac{\boldsymbol{n}}{\mathbf{2}}+\frac{\mathbf{2 1}}{\mathbf{2}},(n$ indicates odd number of throwing the ghoen into the air)and similarly the number of stones placed into the hole can be demonstrated as $\boldsymbol{f}(\boldsymbol{m})=-\frac{\boldsymbol{m}}{\mathbf{2}}+\mathbf{1 0},,(m$ indicates even number of throwing the ghoen into the air $)$. The other observation which came clear from the table is that as the number of throws increases, the number of stones either scooped or placed into the hole decreases. The research participants felt that their knowledge is respected and hope that it can produce better results.

It is important that marginalised knowledge be accepted and valued in schools as it will help to narrow the gap between excluded and non-marginalised children in the teaching and learning of problem solving. The exchange of knowledge is of mutual benefit, as in the long run excluded communities are empowered to conduct such cultural activities (indigenous games), which are rich in mathematical content. 
Cultural contexts of the learners are not emphasised in the teaching and learning of mathematics

The core instruction of mathematics should be the realisation of learners' own contexts, cultures and experiences. Learners can engage in games such as dominoes (Leonard, 2008:162) and indigenous games, which appeal to both children and adults. A game such as kgati (rope jumping) can help them understand curves, parabolic curves, and maximum and minimum values of the curves. As parents and learners demonstrated the play one learner said, "oh yes I know what movement is described by the skipping rope."

One learner, Mampho argued:

Mampho: ha le letsoho la mme MmaKano le phahama ho bonahala hore kgati e
phahamela hodimo, moo le letsoho la hae le theohelang fatshe, le kgati e theohela fatshe
(As Mrs. MmaKano's hand goes up, it shows the rope is going up, and as the hand goes
down it illustrates that the rope goes down).

The mathematical knowledge/content extracted from this movement of the rope is that, as the rope (resembling the curve) goes up it shows that the curve is increasing, and as the rope goes down it shows that the curve is decreasing. Also, the phrase "hand goes up and hand goes down' demonstrates the movement of the rope or curve along the vertical axis or $y$-axis. The rope shows the repeated movement 'up and down', which denotes the trigonometric function known as the sine functions. The extract further demonstrates that learners are able to visualise the movement of the skipping rope (kgati), and with the assistance of their linguistic capital able to describe its movement. This is in line with the onto-semiotic approach to ostensive-non ostensive dual dimensions, in which the ostensive facet ponders on the visualisation of the material part of the indigenous games. Likewise, the non-ostensive facet is the idealisation process or imagination by which one is elucidating the movement of the skipping rope using mathematical symbols or equation, and it is here that abstraction takes place, a sophisticated process conceptualised by learners through the engagement of ostensive facet, which assisted them to concretise mathematics concepts (Warren \& Miller, 2013:5). (Refer to Table 1 below)

It was easy for learners to interpret mathematics questions such as: "describe the values of the range/domain where the curve is increasing, constant and decreasing, and describe where the graph has the positive, constant and negative slope." This is further illustrated by Table 1 (below). It was easy for the learners to figure out, remembering the play of the skipping rope by which as the hand was raised so the graph increased. Here they could mention the values of $\mathrm{x}$, as the graph increased or decreased. The second question could be answered by using the same idea as a demonstration of the increasing function, which implied that the gradient was positive. As the hand went down the graph decreased and the gradient was negative. On the other hand, at the point at which the hand was not moving (neither increasing nor decreasing) the hand was about to slope downwards. This was the moment when the hand remained constant, and the graph at that point showed that the gradient was zero. Since the graph was neither rising nor falling the stationary point illustrated that the gradient was zero. 


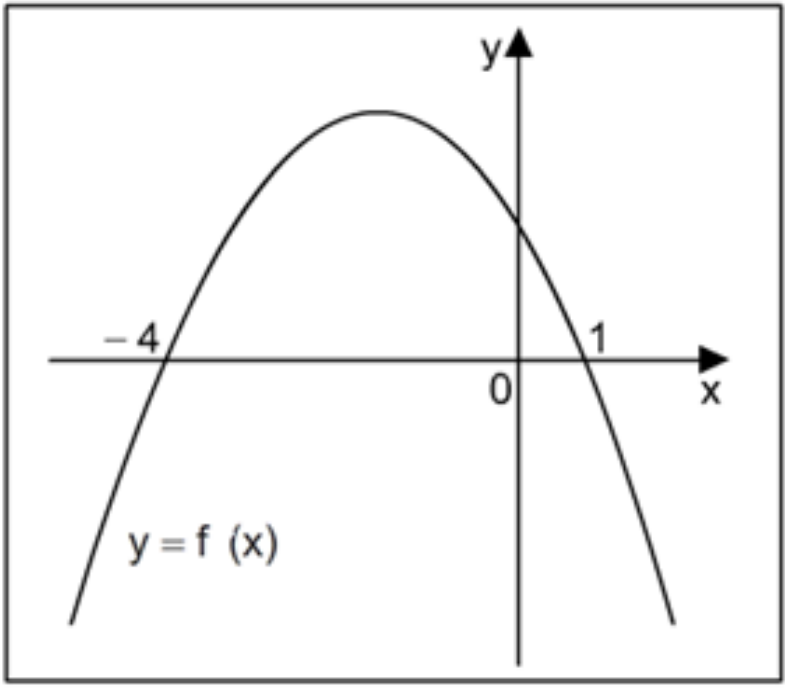

Table 1

There follow examples of questions revealed by the play of kgati, as taught in the Grades 10 12 Mathematics curriculum.

a) The graph of $f(x)$ is increasing and decreasing at which values of $x$

b) When the graph of $f(x)$ is increasing and decreasing, can you describe its steepness or the gradient.

c) When the graph is neither going up nor down, describe its gradient.

The play of kgati demonstrated mathematical concepts such as properties of drawing a cubic graph in differential calculus at Grade 12 level.

The DBE (2011:107) stated that there was also evidence of a poor grasp of the application of calculus when dealing with maxima/minima problems. These concepts can be simplified for learners by using or relating the lesson to indigenous games with which they are familiar. Other mathematical concepts embedded in kgati are 'maximum turning point', at which the gradient or slope of the curve varies from positive gradient, constant gradient to negative gradient. The 'minimum turning point' is reached when the gradient of the curve varies from a negative constant to positive gradient.

Currently, these are typical Grade 12 questions with which most of the learners have difficulties in examinations. This statement supports a discovery by the DBE Report of 2011 (105) that although the concept of gradient is introduced formally in Grade 9 and used in other subjects such as Geography and Physical Sciences, it is poorly understood by many learners at Grade 12 level. The DBE pointed out that these concepts (gradient or steepness of the graph) are covered in certain subjects, such as Geography and Physical Sciences. It might happen that although they are addressed in those subjects it is at the highest level of learners' understanding, or at abstract level, which still makes it difficult for learners to comprehend.

As the theory of community cultural wealth suggests, there is a wealth of knowledge on mathematical content not fully utilised in the mainstream curriculum. In most cases, because of the linguistic capital learners possess they attended secondary Mathematics with a large 
vocabulary and clear grasp of these mathematical concepts embedded within the indigenous games they played at home. Many indigenous games need to be played with learners as a way of bringing closer the knowledge they possess because of their background environment. The Mathematics curriculum taught in relevant and interesting ways makes a significant contribution to learner performance.

\section{Content is too abstract in the teaching of problem solving skills}

The teaching and learning of problem solving skills tend to ignore the cultural background and the context of learners. According to $\operatorname{DoE}(2003: 2)$ 's national curriculum statement policy states that in order to convey precise meanings to the teaching of problem solving its content should not exist in isolation to the context of the world where the learner finds himself or herself in. De Jager (2002:24); Graven \& Schafer (2013:4) added that it is important to affirm what learners know from their home environment, so that it becomes easy for them to acquire new problem solving skills to what already exists in their knowledge schema.This will assist learners of the subaltern community to get access to mathematics with regard to problem solving skills.

Similarly, DoE (2003:2) through its outcomes-based education (OBE) principles states that prior learning needs to be recognised in the teaching of problem solving skills. This helps to integrate the new knowledge on problem solving skills to the cultural background knowledge on problem solving skills gained through interaction with the society. New knowledge taught in class to learners is easily concretised. In such a instances the teaching and learning of problem solving skills do not rely solely on prescribed textbooks, but it is diversified on various teaching and learning materials, which include hands-on- activities. Such activities stimulate the mental thinking of the learners to contextualise knowledge and retain the gained information for long-term duration. The gained knowledge on problem solving skills can be applied to unfamiliar problem solving skills which learners might be confronted with in an authentic environment.

On the other side, the observations were made in the research sites that, the teaching and learning of problem solving skills are taught in such a way that it is not easy for learners to comprehend and relate them to their daily life activities. In the following subtopics, lesson preparation, classroom presentation and assessment of activities will demonstrate how the teaching and learning of functions, algebraic equations and geometry skills are still abstracted in the actual classroom teaching. What follows is an example of the pattern of teaching problem solving skills observed as problematic at the schools under investigation.

\section{Conclusions}

The discussion shows the inclusion of stakeholders such as parents and community leaders in teaching of problem-solving in Grade 10 Mathematics can make significant contributions to improving performance. As Perso (2003:1) argues, such working together helps to bridge the gap between the family, community environment and the classroom environment. Furthermore, Leonard (2008:165, University of the Free State Integrated Report, 2012:11) points out that substantial investment in human capital (knowledge and skills), cultural and social capital (relationships among partners and beneficiaries in education) are essential in sustaining the legacy for academic success (learning and teaching of mathematics) and 
economic wellbeing of the subaltern communities. The teaching and learning of problemsolving in mathematics should incorporate the cultural identities that diverse learners bring to the classroom.

The other point worth mentioning is mathematical concepts and skills, which comes spontaneously through the use of cultural practices such as indigenous games. The throwing of the ghoen into the air is seen as the independent variables and scooping or placing the stones into the hole is regarded as depedent variables. The relationships between the throwing of the ghoen into the air and scooping and placing of the stones into the hole can described as $f(n)=-\frac{\boldsymbol{n}}{\mathbf{2}}+\frac{\mathbf{2 1}}{\mathbf{2}}$ and as $f(m)=-\frac{\boldsymbol{m}}{\mathbf{2}}+10$ respectively. The movement of kgati shows concretised the understanding of increasing and decreasing functions. Although the movement of the rope was for fast to an extent that is was not easy to realise where the rope turns, there was an imaginary point where it became stationary. That stationary point is where the rope turns to make concave and convex.

\section{Rerefences}

The Australian Association of Mathematics Teachers (2006). Standard for Excellence in Teaching Mathematics in Australian Schools. AAMT, Adelaide.

Baquedano-Lopez P; Alexander RA; Hernandez SJ (2013). Equity issues in Parental and Community Involvement in Schools: What teacher Educators Need to know. Review of research in Education, Vol 37,149-182 University of California, Berkeley.

Barton, B (2008). Cultural and Social aspects of mathematics education: Responding to Bishop's challenges, in Critical Issues in Mathematics education: Major contributions of Alan Bishop, Springer Science + Business Media, NY.

Berwick C \& Bennet J (2008). Working with Aboriginal Communities Revised edition 2008 A Guide to Community Consultation and Protocols. Board of Studies NSW, Australia

Brydon-Miller M, Kral M, Maguire P, Noffke S and Sabhlok A (2011). Jazz and the Banyan Tree: Roots and Riffs on Participatory Action Research, in The SAGE Handbook of Qualitative Research, eds (Denzin NK, Lincoln YS), SAGE Publications, USA.

Cameron, ES; de Leeuw S; Greenwood ML (2012). Participatory and community-based research, Indigenous geographies, and the spaces of friendship: A critical engagement. The Canadian Geographer, 56(2): 180-194.

Chilisa B (2012) Indigenous Research Methodologies. SAGE Publications, USA.

Department of Education (2003). National Curriculum Statement Grades 10 -12 (General), Pretoria.

Department of Basic Education (2009). National Examinations and Assessment Report on the National Senor Certificate Examinations Results, Pretoria.

Department of Basic Education (2011). Mathematics: Curriculum and assessment Policy statement Grades 10-12, Pretoria.

Font V, Godino JD, D'amore B (2007).An onto-semiotic approach to representations in Mathematics education. Journal For the Learning of Mathematics, Vol. 27, No. 2, pp. 2- 7,FLM Publishing Association. 
Francis, D (2012). Teacher Narratives on the teaching of Sexuality and HIV/ADS education. In Mahlomaholo MG \& Francs, D (eds). Communitas (special edition), vol 12, pp.45 59. Unit for Community Communications of the Department of communication, UFS, Bloemfontein.

Gerdes, P (2001). Exploring the Game of "Julirde": A Mathematical-Educational Game Played by Fulbe Children in Cameroon: Teaching Children Mathematics Focus Issue: Mathematics and Culture, Vol. 7, No. 6, pp. 321-327.

Graven, M \& Schafer, M (2013). Interview with a mathematics Doodler - Dr Sizwe Mabizela, Deputy Vice Chancellor, Rhodes University, A journal of Amesa,Learning \& Teaching Mathematics, eds, Bizony, M \& Tshabalala, L, No.4, Grahamstown, RSA.

Howard, P \& Perry B, (2008).The Mathematics in Indigenous Contexts Project. APMC 13 (4), 4-9.

Leornard, J (2008). Culturally Specific Pedagogy in the Mathematics Classroom: Strategies for Teachers and Students (First Edition).Rutledge Taylor \& Francis Group, New York.

Leung, F (2008). Chinese culture, Islamic culture, and Mathematics Education, in Critical Issues in Mathematics education: Major contributions of Alan Bishop, Springer Science + Business Media, NY.

Maistry, SM (2012). Foregrounding a Social Justice Agenda in Economic Education: Critical Reflections of a Teacher Education Pedagogue. Journal for new Generation Sciences, Vol. 30, no. 1, 14 - 29,. Central University of Technology, Free State.

Mahlomaholo, MG (2012): Grade 12 Examinations Result' Top 20 positions: The need for the creation of sustainable learning environments for Social Justice in All Schools. Journal for new Generation Sciences, Vol. 30, no. 1, 14 - 29,. Central University of Technology, Free State.

Mahlomaholo, MG (2012). Early School leavers and sustainable learning environments in rural contexts. Perspective in Education, Vol 30, no1, 101 - 110.

Mahlomaholo S MG (2012). Social communication towards sustainable Physical Science learning environments Journal for Community Communication and Information Impact (special Edition), Vol. 17, 3 - 20,. Unit for Community Communication, UFS.

Matthews C, Watego L, Cooper T and Baturo, A (2005) Does mathematics education in Australia devalue Indigenous culture? Indigenous perspectives and non-Indigenous reflections. In Clarkson, Philip and Downton, Ann and Gronn, Donna and Horne, Marj and McDonough, Andrea and Pierce, Robyn and Roche, Anne, Eds. Proceedings 28th conference of the Mathematics Education Research Group of Australasia Vol. 2, pages. 513-520, Melbourne, Australia.

McGregor, SLT \& Murnane, JA (2010). Paradigm, methodology and method: Intellectual integrity in consumer scholarship. International Journal of Consumer Studies, 34(4), 419427.

Moana, E (2010). Ma Te Whānau Te Huarahi Motuhake: Whānau Participatory Action Research groups. MAI Review, 3, pp. 1-9. 
Odora-Hoppers CA (2000). The Centre-periphery in Knowledge Production in the Twenty-.first Century, British Association for International and Comparative Education, London.

Perakyla A, Ruusuvuori, J (2011). Analysing Talk and Text, in The SAGE Handbook of Qualitative Research, eds (Denzin NK, Lincoln YS), SAGE Publications, USA.

Perso, T.F. (2003) “Improving Aboriginal Numeracy", Australian Association of Mathematics Teachers: Adelaide.

Reddy BV (2006). The state of Mathematics and Science education: schools are not equal, chapter in The state of the Nation: South Africa 2005 - 2006 by Buhlungu S, Daniel J, Southall R, Lutchman J(eds) .HSRC Press. Cape Town.

Rocha-Schmidt E (2010). Participatory pedagogy for empowerment; A critical discourse analysis of teacher-parents' interactions in a family literacy course in London. International Journal of Life Long Education. Vol 29(3), 343 - 358, University of Birmingham, UK.

Ruthven K (2001).Issues of cultural diversity in school mathematics. International Journal of Mathematical Education in Science and Technology vol. 32, no. 3, 355-364 Taylor \& Francis Ltd, UK.

Tucker, K (2010). Mathematics through Play in the early Years (2 ${ }^{\text {nd }}$ Edition). Sage Publications Ltd, London.

University of the Free State Integrated Report (2012). UFS Integrated Report 1 January 31 December 2012, Bloemfontein

Van Laren, L, \& Goba, B (2013). They say we are crèche teachers: Experiences of pre-service mathematics teachers taught through medium of isiZulu. Pythagoras,34(1),21 -28

Vithal, R; Adler, J \& Keitel (2005). Researching Mathematics Education in South Africa : Perspectives, Practices and Possibilities. Cape Town: HSRC Press

Warren E \& Miller J(2013).Young Australian Indigenous students' effective engagement in mathematics: the role of language Patterns and structure. Mathematics Education Research Journal, Mathematics Education Research Group of Australasia, Inc., Australia.

Wodak R, Meyer M (2009). Critical discourse analysis: History, agenda, theory and methodology. In Wodak, R \& Meyer, M. (eds). Methods of critical discourse analysis. London: Sage.

Yosso (2005:76). Whose culture has capital? A critical race Theory discussion of community cultural wealth. Race ethnicity and Education 8(1): 69 - 91. 